\title{
ADVERTISING APPEALS AND A PSYCHOLOGICAL SCARCITY EFFECT: COMPETITIVE AROUSALS AND IMPLICATIONS ON PURCHASE INTEREST
}

\author{
Bridget Satinover Nichols, Northern Kentucky University, USA
}

\begin{abstract}
Economic theory stipulates that companies compete as a natural force of the free market system. Within the same theory, assumptions about how consumers respond to supply and demand fluctuations are made without due consideration for many tenets of consumer behavior like perceptions or attitudes. Only recently have researchers begun to explore the "human" effect of supply and demand, concentrating on scarcity-based situations (Brannon and McCabe 2010; Lynn 1989). These studies have focused largely on scarcity's ability to increase desirability for goods, suggesting this occurs through mechanisms of perceived value (Lynn 1991), and consumers' needs for uniqueness (van Herpen et al. 2005), since people who desire individuality recognize that owning scarce goods can create this distinction. Research indicates that advertisements with scarcity appeals lead to enhanced value perceptions and purchase intentions for scarce goods (Eisend 2008), because they create a sense of "missing out." Behaviorally, the scarcity effect influences people's tendency to attempt acquisition of resources that are scarce or becoming scarcer (Cialdini 1995). Evidence of this can be found with respect to auctions (Ariely and Simonson 2003; Ku et al. 2004), Black Friday shopping (Harrison, Reilly, and Gentry 2010), and special retail events (Nichols 2010).

Researchers consider the use of scarcity tactics a persuasion strategy because scarcity implies competition, and to obtain something scarce implies that one has won the competition (Knowles and Linn 2004). In general, consumers' valuation of tangible goods is higher when scarcity is due to increased demand and restricted supply, rather than by accidental supply circumstances (Verhallen and Robben 1994). Besides the product scarcity tactic (e.g. restricted supply), which dominates the literature, time scarcity tactics are also largely employed in advertising. Time scarcity refers to a real or implied limitation on the duration for which an offering can be acquired. Like product scarcity, time scarcity can also evoke fear or threat to choice when consumers fear missing out on an offering and consider anticipated regret (Cialdini 1995). Advertisements with a time scarcity stimulus have shown to increase perceptions and purchase intentions of the advertised product (Eisend 2008).

Despite the proclivity of scarcity-based appeals in marketing and advertising, limited efforts have been made to investigate the "human effect" of these tactics. Similarly, competition and competitiveness is lacking empirical examination in the consumer domain. This paper hypothesizes that scarcity-based advertising appeals will heighten consumer competitive arousal (CCAr; Nichols 2011). Guided by commodity theory (Brock 1968) and the scarcity effect (Cialdini 1995), an experiment tests the effects of product and time advertising scarcity appeals on competitive arousals in a retail context. Consumer competitive arousals were measured with an existing scale (Nichols 2011). Two theoretically relevant personality traits were tested as moderating variables. Findings indicate that scarcity appeals are able to create competitive arousals in consumers, predominantly advertising appeals promoting product supply limitations. The traits of need for uniqueness and interpersonal competitiveness were not supported as moderating variables. Importantly, consumer competitive arousals appear to influence purchase interests of scarce goods.
\end{abstract}

References available upon request 